OPEN ACCESS

Edited by:

Juan Carlos Cutrin,

University of Turin, Italy

Reviewed by:

Moisés Evandro Bauer, Pontifical Catholic University of Rio

Grande do Sul, Brazl

Daniela Frasca,

University of Miami, United States

${ }^{*}$ Correspondence:

Diego T. Brunelli

diegotbrunelli@gmail.com

Specialty section: This article was submitted to Inflammation,

a section of the journal

Frontiers in Immunology

Received: 31 October 2021 Accepted: 09 December 2021

Published: 05 January 2022

Citation:

Brunelli DT, Boldrini VO, Bonfante ILP, Duft RG, Mateus K, Costa L, Chacon-Mikahil MPT,

Teixeira AM, Farias AS and

Cavaglieri CR (2022) Obesity

Increases Gene Expression of Markers Associated With Immunosenescence in Obese Middle-Aged Individuals.

Front. Immunol. 12:806400. doi: 10.3389/fimmu.2021.806400

\section{Obesity Increases Gene Expression of Markers Associated With Immunosenescence in Obese Middle-Aged Individuals}

Diego T. Brunelli ${ }^{1 *}$, Vinicius O. Boldrini ${ }^{2}$, Ivan L. P. Bonfante ${ }^{1}$, Renata G. Duft ${ }^{1}$, Keryma Mateus ${ }^{1}$, Leonardo Costa ${ }^{1}$, Mara P. T. Chacon-Mikahil ${ }^{1}$, Ana M. Teixeira ${ }^{3}$, Alessandro S. Farias ${ }^{2}$ and Cláudia R. Cavaglieri ${ }^{1}$

${ }^{1}$ Exercise Physiology Lab (FISEX) - Faculty of Physical Education, University of Campinas (UNICAMP), Campinas, Brazil, ${ }^{2}$ Autoimmune Research Lab, Department of Genetics, Microbiology and Immunology, Institute of Biology, University of Campinas (UNICAMP), Campinas, Brazil, ${ }^{3}$ Research Center for Sports Sciences and Physical Activity, University of Coimbra, Coimbra, Portugal

Recently, it has been argued that obesity leads to a chronic pro-inflammatory state that can accelerate immunosenescence, predisposing to the early acquisition of an immune risk profile and health problems related to immunity in adulthood. In this sense, the present study aimed to verify, in circulating leukocytes, the gene expression of markers related to early immunosenescence associated with obesity and its possible relationships with the physical fitness in obese adults with type 2 diabetes or without associated comorbidities. The sample consisted of middle-aged obese individuals (body mass index (BMI) between $30-35 \mathrm{~kg} / \mathrm{m}^{2}$ ) with type 2 diabetes mellitus (OBD; $\mathrm{n}=17$ ) or without associated comorbidity (OB; $n=18$ ), and a control group of eutrophic healthy individuals (BMI: $\left.20-25 \mathrm{~kg} / \mathrm{m}^{2}\right)$ of same ages ( $\left.\mathrm{E} ; \mathrm{n}=18\right)$. All groups (OBD, OB and $\left.\mathrm{E}\right)$ performed the functional analyses [muscle strength (1RM) and cardiorespiratory fitness $\left(\mathrm{VO}_{2 \max }\right)$ ], anthropometry, body composition (Air Displacement Plethysmograph), blood collections for biochemical (anti-CMV) and molecular (gene expression of leptin, IL-2, IL-4, IL-6, IL-10, TNF- $\alpha$, PD-1, P16 ink4a, CCR7, CD28 and CD27) analyses of markers related to immunosenescence. Increased gene expression of leptin, IL-2, IL-4, IL-10, TNF- $\alpha$, PD-1, P16 ${ }^{\text {ink4a }}$, CCR7 and CD27 was found for the OBD and OB groups compared to the $\mathrm{E}$ group. Moreover, $\mathrm{VO}_{2 \max }$ for the $\mathrm{OBD}$ and $\mathrm{OB}$ groups was significantly lower compared to $\mathrm{E}$. In conclusion, obesity, regardless of associated disease, induces increased gene expression of markers associated with inflammation and immunosenescence in circulating leukocytes in obese middle-aged individuals compared to a eutrophic group of the same age. Additionally, increased adipose tissue and markers of chronic inflammation and immunosenescence were associated to impairments in the cardiorespiratory capacity of obese middle-aged individuals.

Keywords: type 2 diabetes mellitus, inflammation, aging, physical fitness, adipose tissue 


\section{INTRODUCTION}

Obesity is considered a global health problem, affecting a large part of the population and becoming one of the main causes of reduced quality of life, morbidity and mortality (1-3). Several studies have proposed that the central mechanism underlying obesity and its related comorbidities comes from a persistent state of low-grade chronic inflammation together with dysregulation in the inflammation-stress feedback mechanisms (4-6), mainly due to increased production of pro-inflammatory markers such as leptin, interleukin-6 (IL-6), tumor necrosis factor $-\alpha$ (TNF- $\alpha$ ), C-reactive protein (CRP) and monocyte chemotactic protein - 1 (MCP1) in the withe adipose tissue, together with the M1 macrophage phenotype infiltration in this tissue associated with obesity (6-8).

Furthermore, it has been proposed that dysfunctional adipocytes are involved in the production of oxidative stress through the generation of reactive oxygen species, implicating further inflammation and tissue damage (9). Additionally, there is a consensus that an appropriate defensive immune response requires low levels of oxidation and inflammation interconnected with many feedback loops (10). However, cell damage was seen to appear when these levels were increased (as in the case of obesity) and innate immunity cells, such as macrophages, exhibit an over-activated production of oxidative and inflammatory compounds which occurs mainly in the absence of antigenic stimulus and cannot be neutralized by antioxidant nor anti-inflammatory defenses, thus leading to a chronic state of oxidative and inflammatory stress $(5,10)$.

In addition, increase evidence suggests that the process of aging is the result of the accumulation of cellular damage caused by oxidative and inflammation stress throughout the lifetime of an organism, where the immune system seems to be involved in this stress and in the rate of aging $(5,11)$. Thus, given the context of neuro-immune-endocrine communication and its changes in oxidative and inflammatory situations, as well as the impairment of the immune system, characteristics similar to those observed in aging, it has been speculated that obesity generates premature immunosenescence (biological aging of the immune system), and this may be one of the reasons for the increased rate of morbidity and risk of death related to this disease (12-15).

Immunosenescence has a number of hallmark features such as increased activities of immune cells and progressive decline in the functional activity of phagocytic cells, natural killer cells, lymphoproliferative response and mitogen-stimulated cytokine production (16-18), accumulation of late-differentiated subsets of $\mathrm{T}$ lymphocyte accompanied by lowered proportions of naïve $\mathrm{T}$ cells and seropositivity for latent cytomegalovirus (CMV) and Epstein-Barr virus (EBV) infections $(15,18,19)$, these changes being associated with poor vaccine efficacy, decreased immune surveillance and increased morbidity and mortality as a result of infectious diseases (19-21). In fact, studies show that obese individuals have a higher prevalence and severity of persistent viral infections, such as the herpes simplex virus type 1 - (HSV1) (22) and SARS-CoV-2 (21) and a lower immune response to infections by pathogens and vaccines $(23,24)$, thus indicating the presence of a less competent immune system when compared to non-obese individuals with similar age.

Furthermore, it has been postulated that the presence of senescent cells may be the causative agent in the development and progression of type 2 diabetes (T2D) and contributes to tissue dysfunction; however, the diabetic milieu might permit the development of senescent cells (25). Additionally, it has been shown that increased presence of senescent $\mathrm{T}$ cell has a detrimental impact on the immune function of obese people living with T2D (26). Thus, the need for studies that investigate the adverse effects of obesity with or without associated comorbidity on the various factors related to immunosenescence is evident. Given this context, the present study aimed to verify the effects of obesity per se or with associated comorbidity T2D on the gene expression of pro and anti-inflammatory and senescence markers of the immune system in circulating leukocytes and their correlations with physical fitness in obese middle-aged adults with T2D or without associated disease.

\section{MATERIALS AND METHODS}

\section{Subjects and Study Design}

The project was publicized by means of fliers, posters in the university campus, internet, advertising in city newspapers and by visits to places such as public town squares and malls. The inclusion criteria adopted were as follows: middle-aged (40 - 60 years old) male or female classified as obese [(body mass index $\left.(\mathrm{BMI})>30 \mathrm{~kg} \cdot \mathrm{m}^{-2}\right)$ ] with T2D or with absence of an associated disease or middle aged individuals of both sexes' eutrophics (BMI between $20-25 \mathrm{~kg} / \mathrm{m}^{2}$ ) who had not participated in regular exercise and/or dietary programs over the last 12 months preceding the start of the study, according to the Baecke Habitual Physical Activity Questionnaire (27). Furthermore, volunteers should be non-smokers. Specifically in relation to the female sex, the volunteers had to be postmenopausal.

Initially, 228 subjects were recruited; however, 145 were excluded at the initial interview for not meeting the inclusion criteria and/or for having any feature covered by the exclusion criteria. Exclusion criteria included the following: coronary artery disease, severe hypertension, type 1 diabetes mellitus or insulin-dependent, chronic obstructive pulmonary disease, limiting osteo-articular diseases, or were using any medication that could interfere in the physiological responses of evaluations. Of the 83 subjects who were selected, 65 were approved on clinical examination and exercise electrocardiogram (ECG); however, 12 volunteers were excluded according to the discontinuity criteria which were: lack of motivation or availability of the volunteer in attending the evaluation sessions or other risks that might occasionally arise, even after clinical release. Thus, after the initial evaluations, the middleaged volunteers were allocated to each specific group: obese with T2D (OBD; $\mathrm{n}=17 ; 7$ males and 10 females); obese with absence of associated disease (OB; $\mathrm{n}=18 ; 9$ males and 9 females); and the eutrophic group ( $\mathrm{E} ; \mathrm{n}=18 ; 9$ males and 9 females). All 
volunteers in the OBD group were using metformin to treat T2D.

All groups (OBD, $\mathrm{OB}$ and $\mathrm{E}$ ) performed the functional analyses [muscle strength (1RM) and cardiorespiratory fitness $\left.\left(\mathrm{VO}_{2 \max }\right)\right]$, anthropometry, body composition (Air Displacement Plethysmograph), blood collections for biochemical (anti-CMV) and molecular (gene expression of leptin, IL-2, IL-4, IL-6, IL-10, TNF- $\alpha$, PD-1, P16 ${ }^{\text {ink4a }}$, CCR7, CD28 and CD27) analyses of markers related to immunosenescence at baseline. All evaluations were performed with the volunteers under conditions of spontaneous breathing of atmospheric air, in a room with an average ambient temperature of $23^{\circ} \mathrm{C}$. In order to familiarize themselves with the location, tests and equipment used, the volunteers were invited to visit the premises used for the evaluations and an explanation of the procedures to be used were given.

All the experimental methods and procedures adhered to the Helsinki declaration and were all approved by the local University Research Ethics Committee (CAAE: 55952516.6.0000.5404). Additionally, all participants were informed about the purpose and risks of the study and signed an informed consent document before participation.

\section{Anthropometric Measures and Body Composition}

Height was measured using a wall-mounted stadiometer with a precision of $0.1 \mathrm{~cm}$, and the weight was taken using a calibrated manual scale (Filizola ${ }^{\circledR}$ S.A., São Paulo, SP, Brazil) with a precision of $0.1 \mathrm{~kg}$. The BMI was calculated by dividing body mass $(\mathrm{kg})$ by height squared $\left(\mathrm{m}^{2}\right)$. Waist circumference was measured at the midpoint between the last ribs and the iliac crests with an inelastic metric tape, with the precision of $0.1 \mathrm{~cm}$. The measurement was performed in triplicate by the same trained professional and the average of these three measurements was calculated.

Body composition of the volunteers was estimated by plethysmography in the Bod Pod ${ }^{\mathrm{TM}}$ (COSMED USA, Inc., Concord, CA) body composition system. The same investigator performed all measurement assessments.

\section{Dietary Intake Assessments}

Food records were given to the participants by trained researches who instructed them individually through a presentation of an already completed model food record and photographs of model home measures. They were instructed to complete food records for three nonconsecutive days (two days in the week and one day at the weekend) and the mean of the three food records was used as the dietary intake of each subject. Total calories, carbohydrates, lipids and protein were calculated using the DietPro ${ }^{\circledR}$ Software program, version $5 \mathrm{i}$ (Viçosa, Minas Gerais/Brazil).

\section{Maximal-Strength Assessments}

Maximal-strength for upper- and lower-body was measured by a one-repetition maximum (1RM) test on bench press and leg press. The test protocol was conducted on RIGUETTO ${ }^{\circledR}$ equipment's (São Paulo/Brazil). Subjects were required to perform 10 repetitions at $50 \%$ of their estimated $1 \mathrm{RM}$ (according to each participant's capacity). After $3 \mathrm{~min}$ of rest, subjects were required to perform 3 repetitions at $70 \%$ of their estimated 1RM. Another $3 \mathrm{~min}$ of rest was applied and then subsequent trials were performed for 1RM with progressively heavier weights until the 1RM was determined within three attempts, with 3-5 min of rest between trials (28).

\section{Cardiorespiratory Assessment}

The cardiorespiratory assessment was performed using a progressive effort protocol on a treadmill (Quinton, model TM55, USA), with a continuous collection of expired gases breath to breath (CPX Ultima, MedGraphics, USA). The cardiorespiratory fitness verified by the maximum oxygen consumption $\left(\mathrm{VO}_{2 \max }\right)$ was determined by the average values of the last $30 \mathrm{~s}$ of the test (29).

\section{Blood Sampling and Analysis}

Approximately $10 \mathrm{ml}$ of blood was collected from the antecubital vein into Vacutainer ${ }^{\circledR}$ tubes (Becton Dickinson Ltd, Oxford/ England) for plasma samples (containing anticoagulant EDTA), in the morning (07:00 - 09:00 a.m.), after a 12 hour overnight fast and at least 72 hours before the physical and functional evaluations. Additionally, all individuals were instructed not to consume caffeine and alcohol 24 hours before collection. All samples were collected, processed, divided into aliquots, and stored at $-80^{\circ} \mathrm{C}$ for subsequent analysis. Peripheral blood leukocytes were separated by density gradient centrifugation using Histopaque ${ }^{\circledR}$ (Histopaque ${ }^{\circledR}$ - 1077, Sigma, MO, USA). Plasma glucose analysis was performed using the GOD-Trinder method. Anti-CMV analysis was determined by enzyme-linked immunosorbent assay (ELISA), according to the specifications of the manufacturer (Novus Biologicals, catalog number KA1452, Abnova ${ }^{\circledR}$ Corporation, USA).

Additionally, the extraction of the total leukocyte mRNA was performed following the instructions of the Trizol ${ }^{\circledR}$ reagent. At the end of the extraction of the total RNA, the purity and quantity of the RNA of the samples were verified in the Gene Quant ${ }^{\circledR}$ spectrophotometer (Pharmacia Biotech), paying attention to the 260/280 ratio (possible contamination with protein). All the ratios found in the samples were between 1.8 - 2.0 and the samples were considered optimal for use. For the production of the cDNA, we used the High Capacity cDNA Reverse Transcription Kit ${ }^{\circledR}$ (Applied Biosystems, CA, USA), and followed the manufacturer's instructions. The gene expression of leptin, IL-2, IL-4, IL-6, IL-10, TNF- $\alpha$, PD-1, P16ink4a, CCR7, CD28 and CD27 of circulating leukocytes was performed in duplicate using the Real Time Polymerase Chain Reaction (RTPCR) technique, following the descriptions of Pradella etal. (30). The human HPRT primer was used as the reference gene for the reaction (endogenous control). A minimum of $15 \mathrm{ng}$ cDNA per reaction was used for all genes in order to ensure the efficiency of the RT-PCR reaction. All cDNAs were placed in a set of primers and a probe marked with SYBR Green. As for the list of primers, the following 5' and 3' sequences were used: HPRT (forward: G A C C A G T C A A C A G G G G A C A T, rever s e : 
AACACTTCGTGGGGTCCTTTTC); Leptin (forward: GGCTTTGGTCCTATCTGTCTTATGTTC; reverse: CCTGTTGATAGACTGCCAGAGTCTG); CD27 (forward: A C T A C T GG G C T C A G GGA A A G C T; reverse: GGATCACACTGAGCAGCCTTTC); CD28 (forward: GA GA A GA GCAA TGGA A C CA TTA TC; reverse: TAGCAAGCCAGGACTCCACCAA); P16 ${ }^{\mathrm{INK} 4 \mathrm{a}}$ (forward: G G G G G C A C C A GA G G C A G T ; reverse: GGTTGTGGCGGGGGCAGTT); PD-1 (forward: C G T G G C C T A T C C A C T C C T C A ; reverse: ATCCCTTGTCCCAGCCACTC); IL-2 (forward: GAATCCCAAACTCACCAGGATGCTC; reverse: TAGCACTTCCTCCAGAGGTTTGAGT); IL-6 (forward: G G T A C A T C C T C G A C G G C A T C T ; reverse: GTGCCTCTTTGCTGCTTTCAC); IL-10 (forward: C C G T G G A G C A G G T GA A GA A T G; reverse: AGTCGCCACCCTGATGTCTC); IL-4 forward: A A C T T T G T C CA C GGA CA CAA GTGC; reverse: GAATCGGATCAGCTGCTTGTGCCT); CCR7 (forward: G C C C A G A T G G T T T T T G G G T T C; reverse: GCAAGGTACGGATGATAATGAGG); TNF- $\alpha$ (forward: C GA G T C T GGG C A G G T C T A C T T T; reverse: AAGCTGTAGGCCCCAGTGAGTT).

\section{Statistical Analysis}

Initially, the data was organized according to the following groups: Obese diabetic (OBD) or Obese without associated disease $(\mathrm{OB})$ or Eutrophic (E). Then, the data distribution was tested with the Shapiro-Wilk test. From data distribution (parametric or non-parametric), verification of normality and the presence of outliers, the appropriate statistics were applied to verify the differences between the groups studied: one-way Analysis of Variance (ANOVA) for the parametric variables (age, mass, height, waist circumference, $\mathrm{VO}_{2 \max }$, bench press, leg, fat mass, fat-free mass, carbohydrate, protein, lipids and total calories), and when an interaction was observed, Tukey's posthoc test was applied; Kruskal-Wallis test for non-parametric variables (BMI, blood glucose and gene expression of leptin, IL-2, IL-4, IL-6, IL-10, TNF- $\alpha$, PD-1, P16 ${ }^{\text {ink4a }}$, CCR7, CD28 and CD27), and when an interaction was pointed out, DunnBonferroni's post-hoc test was applied. The association between physical fitness and body composition with the gene expression of the immunosenescence markers used in the present study was tested by Spearman's correlation test. All the data were analyzed using the IBM ${ }^{\circledR}$ SPSS $^{\circledR}$ Statistics 20.0 (IBM Corp. ${ }^{\circledR}$ Copyright IBM Corporation, USA) software program. The level of significance was set at $\mathrm{p} \leq 0.05$. All data are presented in values of mean $\pm \mathrm{SD}$.

\section{RESULTS}

All volunteers did not perform any systematic physical activities in the period prior to the study and were classified as irregularly active according to the Baecke questionnaire, with the times of weekly physical activity reported as follows: $\mathrm{OBD}=65.03 \pm$
$8.08 \mathrm{~min} ; \mathrm{OB}=63.13 \pm 7.08 \mathrm{~min}$; and $\mathrm{E}=68.50 \pm 9.30 \mathrm{~min}$. Furthermore, all volunteers (with the exception of 1 individual in the E group) presented serum positivity for CMV. Thus, we do not separate the results between CMV seropositive or negative individuals.

Table 1 presents the results for anthropometric measurements, body composition and fasting glucose. Significant differences were found for weight, BMI, body fat, fat-free mass, waist circumference and $\mathrm{VO}_{2 \max }$ for $\mathrm{OBD}$ and $\mathrm{OB}$ as compared to $\mathrm{E}$ ( $\mathrm{p}<0.0001$ for all the comparisons). However, there were no differences between $\mathrm{OBD}$ and $\mathrm{OB}$ for these same variables $(p>0.05)$. Additionally, as expected, fasting glucose was significantly higher for OBD as compared to OB $(\mathrm{p}<0.0001)$ and $\mathrm{E}(\mathrm{p}<0.0001)$, without differences between $\mathrm{OB}$ and $\mathrm{E}(\mathrm{p}>$ 0.05). Furthermore, no significant differences were observed in age, height and 1RM of the bench press and leg press between the groups studied ( $\mathrm{p}>0.05)$.

Table 2 presents the results for dietary intake assessments. Carbohydrate ingestion was significantly higher for OBD as compared to OB $(\mathrm{p}=0.038)$ and $\mathrm{E}(\mathrm{p}=0.001)$. Additionally, protein ingestion was significantly lower for $\mathrm{OB}$ as compared to $\mathrm{E}(\mathrm{p}=0.016)$. Furthermore, a tendency of higher total caloric ingestion was observed for OBD $(\mathrm{p}=0.063)$ and $\mathrm{OB}(0.060)$ in comparison to $\mathrm{E}$. There was no significant difference in lipids ingestion between groups $(\mathrm{p}>0.05)$.

Figure 1 represents the values of quantifications relative $(\mathrm{QR})$ to endogenous control (HPRT) of the gene expression of the markers analyzed in the present study. Leptin expression was significantly higher for the $\mathrm{OBD}$ and $\mathrm{OB}$ groups compared to $\mathrm{E}$ ( $\mathrm{p}=0.001$ and $\mathrm{p}=0.047$, respectively; Figure 1A) and also for OBD compared to $\mathrm{OB}(\mathrm{p}=0.020$; Figure 1A). Additionally, gene expression of IL-2 $(p=0.003$ and $p=0.0001$, respectively; Figure 1B $), \operatorname{IL} 4(p=0.001$ and $\mathrm{p}=0.011$, respectively; Figure $1 \mathrm{C}), \mathrm{CD} 27(\mathrm{p}=0.014$ and $\mathrm{p}=$ 0.043 , respectively; Figure 1D), IL10 $(p=0.001$ and $p=0.0001$, respectively; Figure 1E), TNF- $\alpha(\mathrm{p}=0.001$ and $\mathrm{p}=$ 0.029 , respectively; Figure 1F), PD-1 $(\mathrm{p}=0.006$ and $\mathrm{p}=0.003$, respectively; Figure 1G), $\mathrm{P} 16^{\text {ink4a }}(\mathrm{p}=0.014$ and $\mathrm{p}=$ 0.029 , respectively; Figure 1J) and CCR7 $(\mathrm{p}=0.0001$ and $\mathrm{p}=$ 0.012, respectively; Figure 1K) were significantly higher for OBD and $\mathrm{OB}$ compared to $\mathrm{E}$, with no difference between $\mathrm{OBD}$ and $\mathrm{OB}$ for these same variables ( $p>0.05$ for all the comparisons). On the other hand, gene expression of IL-6 showed significant higher only for the $\mathrm{OB}$ group compared to $\mathrm{E}(\mathrm{p}=0.038$; Figure $1 \mathrm{II})$, with no difference when comparing the $\mathrm{OBD}$ group to $\mathrm{OB}(\mathrm{p}=1.00)$ and $\mathrm{E}$ $(p=0.253)$. There were no significant differences for CD28 in the comparison between the groups studied ( $p>0.05$ for all comparisons; Figure 1H).

As regards the correlations between the physical fitness and body composition variables, significant negative correlations were observed between $\mathrm{VO}_{2 \max }$ and $\mathrm{BMI}(\mathrm{r}=-.504, \mathrm{p}=$ $0.0001)$ and $\mathrm{VO}_{2 \max }$ and body fat $(\mathrm{r}=-.762, \mathrm{p}=0.0001)$. In addition, a significant correlation was found between $\mathrm{VO}_{2 \max }$ and fat-free mass $(r=.762, p=0.0001)$. Furthermore, the correlations between physical fitness and body composition with the gene expression of the immunosenescence markers analyzed in the present study are shown in Table 3. 
TABLE 1 | Anthropometric measurements, body composition, functional capabilities and fasting glucose of obese diabetic (OBD) or Obese without associated disease (OB) or Eutrophic (E) middle-aged individuals.

\begin{tabular}{|c|c|c|c|}
\hline & OBD (n = 17) & OB $(n=18)$ & $E(n=18)$ \\
\hline Age (years) & $52.4 \pm 5.0$ & $50.2 \pm 5.5$ & $52.5 \pm 4.4$ \\
\hline Height (m) & $1.66 \pm 0.08$ & $1.69 \pm 0.10$ & $1.69 \pm 0.11$ \\
\hline Weight (Kg) & $88.6 \pm 9.3^{\&}$ & $93.6 \pm 13.3^{\&}$ & $68.2 \pm 10.1$ \\
\hline BMI $\left(\mathrm{kg} / \mathrm{m}^{2}\right)$ & $32.3 \pm 2.2^{\&}$ & $32.5 \pm 1.5^{\&}$ & $23.8 \pm 1.4$ \\
\hline Body fat (\%) & $39.9 \pm 6.4^{\&}$ & $43.9 \pm 7.7^{\&}$ & $26.8 \pm 8.1$ \\
\hline Fat-free mass (\%) & $60.1 \pm 6.3^{\&}$ & $56.1 \pm 7.7^{\&}$ & $73.3 \pm 8.0$ \\
\hline Waist circumference (cm) & $101.6 \pm 5.7^{\&}$ & $101.3 \pm 8.2^{\&}$ & $85.1 \pm 8.1$ \\
\hline Fasting glucose (mg/dL) & $142.1 \pm 36.6^{\star \&}$ & $89.3 \pm 8.8$ & $87.5 \pm 7.6$ \\
\hline $\mathrm{VO}_{2 \max }(\mathrm{ml} / \mathrm{kg} / \mathrm{min})$ & $20.92 \pm 4.59^{\&}$ & $22.43 \pm 5.33^{\&}$ & $29.30 \pm 4.67$ \\
\hline 1RM - bench press (Kg) & $31,5 \pm 14,6$ & $31,4 \pm 17,8$ & $25,7 \pm 13,6$ \\
\hline 1RM - leg press (kg) & $208,8 \pm 57,8$ & $204,7 \pm 62,5$ & $165,3 \pm 46,5$ \\
\hline Diabetes duration (years) & $5,2 \pm 3,1$ & - & - \\
\hline
\end{tabular}

BMI, body mass index. *Significantly different from $O B$; ${ }^{\&}$ Significantly different from $E ; p \leq 0.05$.

\section{DISCUSSION}

Over time, scientific evidences have elucidated that obesity is a complex disorder and a major risk factor for many diseases and health problems such as cardiovascular diseases, T2D, cancer, among others (31). Additionally, based on similar characteristics for cellular senescence as those observed in aging, obesity has been linked to the development of early immunosenescence and decreases in life span $(12-15,31)$. In animal models used in experimentation, Hunsche et al. (5) observed that macrophage and lymphocyte chemotaxis, macrophage phagocytosis, NK cell activity, lymphocyte proliferative response, secretion of IL-1 $\beta$, TNF- $\alpha$, IL-6, IL-2 and IL- 10 in leukocyte cultures, as well as the antioxidant and oxidative capacity of obese adult rats were significantly impaired when compared to non-obese adult rats and similar to elderly rats, thus concluding that obesity can generate premature immunosenescence that is aggravated as the obese adult rat ages. In agreement with these finding, studies have shown that obesity and diabetes accelerate biological ageing and consequently the appearance of age-related diseases especially through premature induction of the senescent state $(26,31-33)$. Results presented herein show that obesity, regardless of associated disease (such as type 2 diabetes mellitus), induces increased gene expression in circulating leukocytes of markers related to chronic inflammation and to senescence of the immune system in obese middle-aged individuals compared to a eutrophic group of the same age. Furthermore, we observed that obesity could lead to impairments in cardiorespiratory fitness which has significant correlations with inflammation and the immunosenescence markers investigated in the present study.
Several studies have shown that the dysfunction in adipose tissue resulting from obesity leads to a chronic inflammatory state firstly in all of the adipose tissue but becoming systemic through the release of pro-inflammatory adipokines and cytokines such as Leptin, TNF- $\alpha$, IL-6, IL-8, CRP, MCP1, among others in the peripheral blood circulation $(6-8,34)$. This chronic inflammation associated with obesity directly impacts innate and adaptive immunity cells with both a proinflammatory orientation of immune cells in the basal state and results in a decrease in their ability to respond to infection and re-infection $(6,34)$. In accordance with the previous statements, our results showed increases in gene expression both for markers related to chronic inflammation (leptin, TNF- $\alpha$, IL-2 and IL-6) and for markers related to senescence of the immune system (PD-1, P16 ${ }^{\text {ink4a }}$, CCR7 and CD27) in circulating leukocytes of obese middle-aged individuals when compared to lean individuals of equal age and similar physical exercise habits, regardless of having an associated disease. Despite this, we did not find significant differences as regard CD28 expression. However, the eutrophic individuals showed a tendency to express higher levels of $\mathrm{CD} 28$, in circulating leukocytes, than obese and diabetic individuals. Lack of CD28 expression has been suggested as an important marker of senescent $\mathrm{T}$ cells (35).

We also observed that anti-inflammatory markers (as in the case of IL-10 and IL-4) were more expressed in the circulating leukocytes of obese individuals with or without diabetes when compared to lean individuals. This may be explained, in part, by the overexpression of leptin found in the present study, since the systemic increase in this adipokine increases the proliferation of B lymphocytes, decreases its apoptosis and activates its secretion of cytokines such as TNF- $\alpha$, IL-6 and IL-10 (36). Additionally,

TABLE 2 | Carbohydrates, protein, lipids and total calories ingestion of obese diabetic (OBD) or Obese without associated disease (OB) or Eutrophic (E) middle-aged individuals.

\begin{tabular}{lccc}
\hline & OBD $(\mathbf{n}=\mathbf{1 7})$ & OB $(\mathbf{n}=\mathbf{1 8})$ & $\mathbf{E}(\mathbf{n}=\mathbf{1 8})$ \\
\hline Total calories (Kcal) & $1836.4 \pm 464.2$ & $2122.0 \pm 760.3$ & $1595.8 \pm 454.7$ \\
Carbohydrates (g) & $342.5 \pm 91.9^{* \&}$ & $250.2 \pm 112.2$ & $200.8 \pm 71.7$ \\
Lipids (g) & $62.9 \pm 21.4$ & $74.3 \pm 33.1$ & $58.4 \pm 20.8$ \\
Protein (g) & $80.1 \pm 21.5$ & $70.2 \pm 15.1^{\&}$ & $96.1 \pm 30.0$ \\
\hline
\end{tabular}

*Significantly different from $\mathrm{OB}$; ${ }^{\&}$ Significantly different from $E ; p \leq 0.05$. 

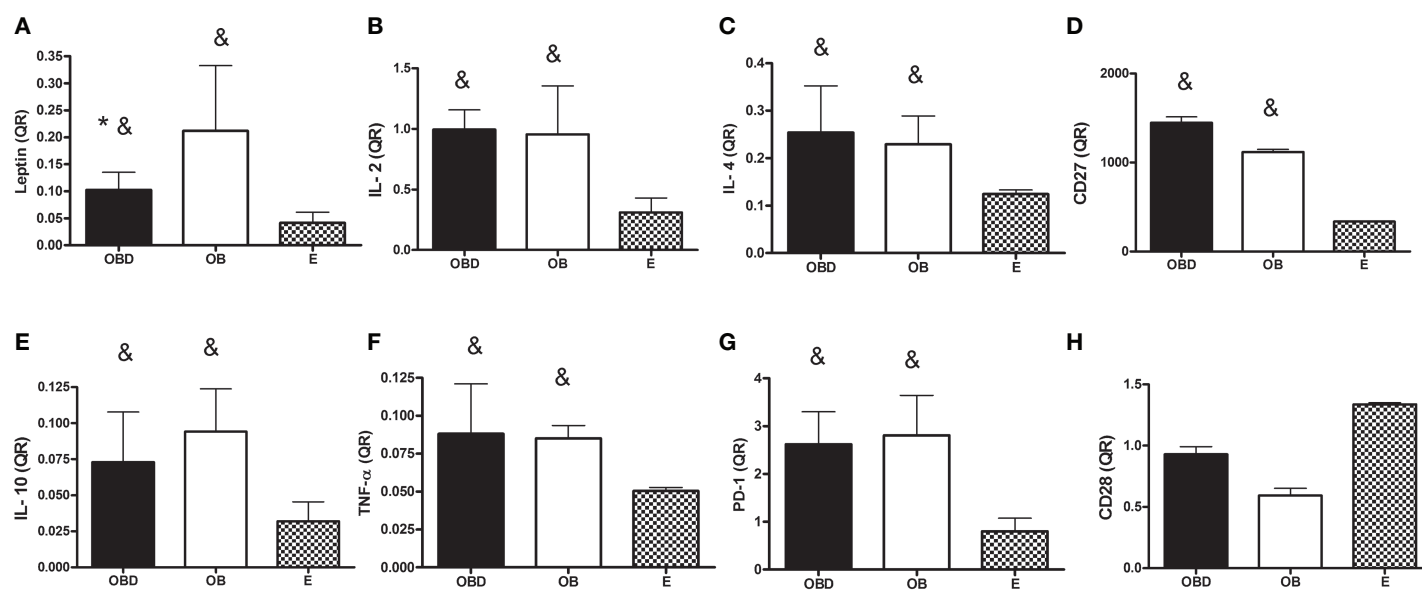

H
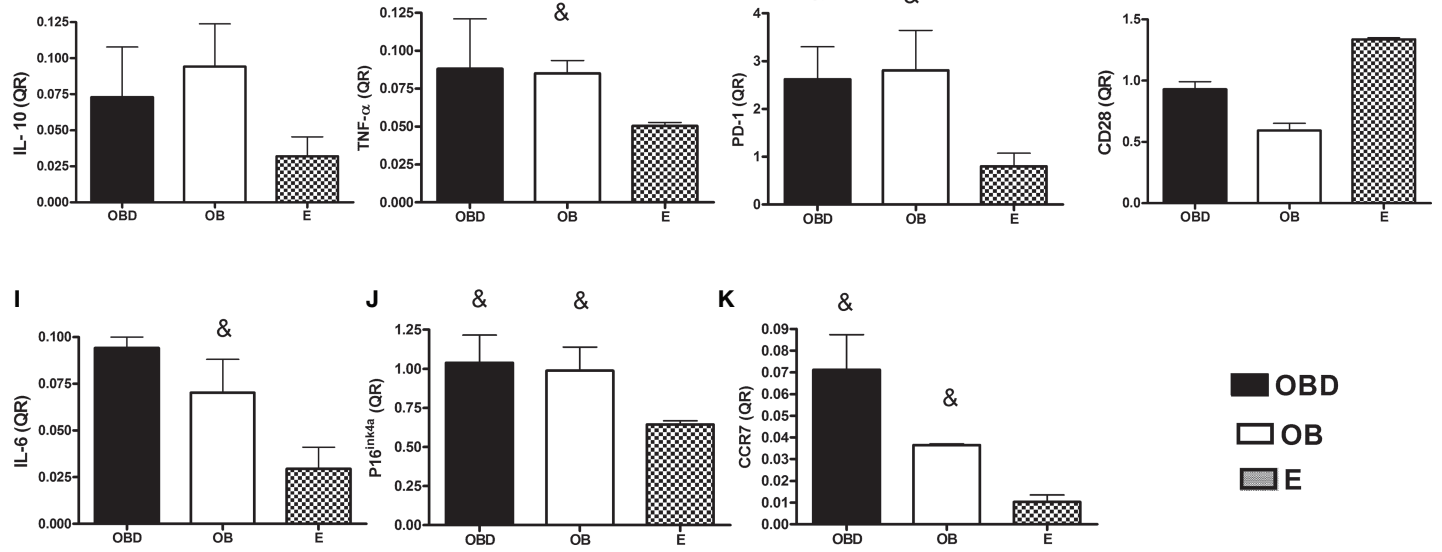

FIGURE 1 | Gene expression of leptin (A), IL-2 (B), IL-4 (C), CD27 (D), IL-10 (E), TNF- $\alpha$ (F), PD-1 (G), CD28 (H), IL-6 (I), P16 $6^{\text {ink4a }}$ (J) and CCR7 (K) in PBMCs of obese diabetic $(\mathrm{OBD})$ or Obese without associated disease (OB) or Eutrophic (E) middle-aged individuals. ${ }^{*}$ Significantly different from $\mathrm{OB} ;{ }^{\text {\& }}$ Significantly different from $E ; p \leq 0.05$

IL-4 is one of the signature cytokines of type II inflammatory response and is the key regulator of activation, growth and differentiation of lymphocyte functions (37). Furthermore, studies have shown that IL-4 and IL-13 mediated IL-4 receptor (IL-4R) signaling in both mouse and human neutrophils inhibits their migration and effector functions in vitro and in vivo (3840). Although IL-4 plays a protective role in inflammation by suppressing pro-inflammatory cytokine production like IFNgamma, TNF- $\alpha$ and IL-1 (41), our results herein may indicate that obesity can contribute to a cascade of pro-inflammatory cytokines that IL-4 are unable to suppress. Thus, according to other studies that also found an increase in IL-4 associated with obesity (42), we speculate that increased expression of IL-4 in the obese groups compared to lean subjects may be due to a compensatory mechanism trying to maintain cell functions, homeostasis and tissue integrity.

In our study, obese middle-aged individuals with T2D or without any associated disease showed higher expression of senescent markers such PD-1 and P16 ${ }^{\text {ink } 4 a}$ when compared to lean middle-aged subjects, thus indicating the presence of a

TABLE 3 | Correlations between physical fitness and body composition with gene expression of the immunosenescence markers of obese diabetic (OBD) or Obese without associated disease (OB) or Eutrophic (E) middle-aged individuals.

\begin{tabular}{|c|c|c|c|c|c|c|c|c|c|c|c|c|}
\hline & & Leptin & IL-2 & IL-4 & IL-10 & TNF- $\alpha$ & PD-1 & IL-6 & P16 ink4a & CCR7 & CD28 & CD27 \\
\hline \multirow[t]{2}{*}{ BMl } & Spearman's correlation & $.498^{\star}$ & $.515^{\star}$ & $.387^{\star}$ & $.483^{\star}$ & .250 & $.360^{\star \star}$ & .271 & .241 & $.570^{\star}$ & -.137 & $.414^{*}$ \\
\hline & Sig. (2-tailed) & .000 & .000 & .005 & .000 & .086 & .010 & .055 & .088 & .000 & .353 & .002 \\
\hline \multirow[t]{2}{*}{$\mathrm{VO}_{2 \max }$} & Spearman's correlation & $-.373^{\star}$ & $-.467^{\star}$ & $-.305^{\star \star}$ & $-.357^{\star \star}$ & -.258 & $-.321^{\star \star}$ & -.197 & -.169 & $-.485^{\star}$ & .148 & $-.517^{\star}$ \\
\hline & Sig. (2-tailed) & .007 & .001 & .033 & .012 & .083 & .026 & .175 & .246 & .000 & .327 & .000 \\
\hline \multirow[t]{2}{*}{ Chest press } & Spearman's correlation & .051 & .101 & .038 & .251 & .212 & -.012 & .077 & .255 & .125 & .187 & -.018 \\
\hline & Sig. (2-tailed) & .726 & .495 & .795 & .082 & .157 & .933 & .602 & .077 & .404 & .220 & .904 \\
\hline \multirow[t]{2}{*}{ Leg press } & Spearman's correlation & .171 & .206 & .157 & $.353^{\star \star}$ & .191 & .074 & .112 & .170 & .258 & .063 & .067 \\
\hline & Sig. (2-tailed) & .239 & .166 & .292 & .014 & .209 & .619 & .455 & .249 & .084 & .682 & .653 \\
\hline \multirow[t]{2}{*}{ Body fat } & Spearman's correlation & $.488^{\star}$ & $.439^{\star}$ & $.339^{\star \star}$ & $.339^{\star \star}$ & .256 & $.395^{\star}$ & .194 & .164 & $.369^{\star \star}$ & -.147 & $.456^{\star}$ \\
\hline & Sig. (2-tailed) & .000 & .002 & .018 & .018 & .089 & .006 & .186 & .265 & .011 & .330 & .001 \\
\hline \multirow[t]{2}{*}{ Fat free mass } & Spearman's correlation & $-.487^{\star}$ & $-.437^{\star}$ & $-.337^{\star \star}$ & $-.338^{\star \star}$ & -.252 & $-.395^{\star}$ & -.197 & -.162 & $-.369^{\star \star}$ & .144 & $-.456^{\star}$ \\
\hline & Sig. (2-tailed) & .000 & .002 & .019 & .019 & .095 & .006 & .180 & .272 & .011 & .341 & .001 \\
\hline
\end{tabular}

${ }^{*}$ Correlation is significant at the 0.01 level (2-tailed); ${ }^{* *}$ Correlation is significant at the 0.05 level (2-tailed); $n=53$. 
premature immunosenescence associated with obesity once PD1 is primarily associated with immune exhaustion (43). In agreement with our results, Wang etal. (44) demonstrated for the first time that obesity increases $\mathrm{T}$ cell aging resulting in higher PD-1 expression and dysfunction, which is driven, at least in part, by leptin signaling. In addition, the expression of $\mathrm{P} 16^{\text {ink4a }}$ increases markedly with aging in most mouse tissues and in human skin and kidney tissues $(45,46)$, which suggests the importance of this tumor suppressor in aging and senescence $(47,48)$. In addition, overexpression of $\mathrm{P} 16^{\text {ink } 4 \mathrm{a}}$ has been reported in senescent fibroblasts (49), in response to oxidative stress $(50,51)$, DNA damage and changes in the structure of chromatin $(52,53)$. However, there is currently no complete understanding of the signs that trigger senescence and, although $\mathrm{P} 16^{\text {ink4a }}$ appears to be one of the main factors in senescence, more information is needed to determine the exact role of each factor in this process (54). Thus, the involvement of PD-1 and P16 ${ }^{\text {ink4a }}$ during inflammation may contribute to increased cell senescence in obesity and type 2 diabetes (55).

The co-receptors CD28 and CD27 have frequently been used to define sub-populations of memory cells, and historically, down-regulation of CD28 was typically associated with loss of functionality, especially with a diminished proliferative capacity and loss of telomeres (56). Although the loss of the co-receptors CD27 and CD28 can be considered to be indicative of impaired telomere function in $\mathrm{T}$ cells and denotes progression towards replicative senescence (57), Colonna-Romano etal. (58) have reported an increase in the percentage of CD27+ B cells and NK cells during aging. Thus, since CD28 expression in our study trend to be lower in the obese groups, we speculate that chronic inflammation associated with obesity increases successive rounds of $\mathrm{T}$ cell proliferation and may induce exhaustion in memory CD8+ T cells, since these cells tend to lose CD28 expression before losing CD27 (57). Additionally, diet-induced obesity does not appear to affect the maintenance of pre-existing long-term memory CD8 + CD27 + T cells, as well as their cytokine production and functions (59). In this regard, since our results point to a negative correlation between the values of $\mathrm{VO}_{2 \max }$ and CD27 expression, it is possible to infer that the persistence of CD27 + cells have some involvement in the context of dysregulation of the respiratory parameter in a systemic inflammatory process as observed in obesity.

Another interesting result found in our study was the higher expression of CCR7 in the obese groups when compared to the lean subject. CCR7 is expressed mainly in including naïve $\mathrm{T}$ cells, central memory $\mathrm{T}$ cells, regulatory $\mathrm{T}$ cells, naïve $\mathrm{B}$ cells, semimature/mature DCs and NK cells, and a minority of tumor cells, and it acts as a key regulator guiding homeostatic lymphocytes to secondary lymphoid organs (60). Studies have shown that CCR7 expression is elevated in response to hypoxia conditions (60) and different types of cancer $(61,62)$. Through the use of animal models, it was possible to demonstrate the involvement of CCR7 in the process of chronic inflammation and insulin resistance. Obese mice knocked out for CCR7 -/- show a decrease in the accumulation of immune cells in adipose tissue, and consequently reduced inflammation. This observation, in turn, is related to increase in glucose uptake in these animals; suggesting that cell migration of CCR7 + populations should influence the local inflammatory process (63).

It must be taken into consideration that this study is not without limitations. First, the lack of specificity of the immunosenescence markers since we did not evaluate the immunophenotyping of circulating lymphocyte subsets. Furthermore, the lack of assessments of protein levels for the soluble mediators coded by the investigated genes and their possible correlations between RNA expression in PBMC and serum/plasma protein levels could bring a better understanding of the effects of obesity to associated early immunosenescence. However, other studies have already demonstrated that the upregulation of gene expression levels of most adipokines in $\mathrm{PBMC}$ is associated with their circulating concentrations, suggesting the contribution of these type of cells to the increased circulating levels in obesity states (64-66).

In conclusion, obesity, regardless of associated disease, induces increased gene expression of markers associated with inflammation and immunosenescence in circulating leukocytes in obese middle-aged individuals compared to a eutrophic group of the same age. Additionally, the increase in adipose tissue and consequently in chronic inflammation and early senescence of the immune system can lead to impairments in the cardiorespiratory capacity of obese middleaged individuals.

\section{DATA AVAILABILITY STATEMENT}

The datasets presented in this study can be found in online repositories. The names of the repository/repositories and accession number(s) can be found in the article/ supplementary material.

\section{ETHICS STATEMENT}

The studies involving human participants were reviewed and approved by Research Ethics Committee of the University of Campinas (CAAE: 55952516.6.0000.5404). The patients/ participants provided their written informed consent to participate in this study.

\section{AUTHOR CONTRIBUTIONS}

$\mathrm{DB}, \mathrm{IB}, \mathrm{RD}, \mathrm{KM}$, and $\mathrm{CC}$ contributed to conception and design of the study. $\mathrm{DB}$ and $\mathrm{VB}$ performed the gene expression analysis. $\mathrm{DB}$ and LC organized the database. DB and RD performed the statistical analysis. DB wrote the first draft of the manuscript. $\mathrm{DB}, \mathrm{VB}$, and AF wrote sections of the manuscript. All authors contributed to manuscript revision, read, and approved the submitted version. 


\section{FUNDING}

The authors would like to acknowledge the financial support (grant $\mathrm{n}^{\circ}$ 2016/08751-3) and post-doctoral fellowship (grant $\mathrm{n}^{\circ}$ 2017/06643-1) provided by the São Paulo Research Foundation (FAPESP). Additionally, the authors thank the National Council for Scientific and Technological Development (CNPq; grant $\left.\mathrm{n}^{\circ} 303571 / 2018-7\right)$ and the Coordination for

\section{REFERENCES}

1. Ng M, Fleming T, Robinson M, Thomson B, Graetz N, Margono C, et al. Global, Regional, and National Prevalence of Overweight and Obesity in Children and Adults During 1980-2013: A Systematic Analysis for the Global Burden of Disease. Lancet (2014) 384:9945. doi: 10.1016/S0140-6736(14)60460-8

2. Endalifer ML, Diress G. Epidemiology, Predisposing Factors, Biomarkers, and Prevention Mechanism of Obesity: A Systematic Review. J Obes (2020) 2020:6134362. doi: 10.1155/2020/6134362

3. Rosengren A. Obesity and Cardiovascular Health: The Size of the Problem. Eur Heart J (2021) 42:34. doi: 10.1093/eurheartj/ehab518

4. Martín-Cordero L, García JJ, Hinchado MD, Ortega E. The Interleukin-6 and Noradrenaline Mediated Inflammation-Stress Feedback Mechanism Is Dysregulated in Metabolic Syndrome: Effect of Exercise. Cardiovasc Diabetol (2011) 10:42. doi: 10.1186/1475-2840-10-42

5. Hunsche C, Hernandez O, de la Fuente M. Impaired Immune Response in Old Mice Suffering From Obesity and Premature Immunosenescence in Adulthood. J Gerontol A Biol Sci Med Sci (2016) 71:8. doi: 10.1093/gerona/ glv082

6. Zatterale F, Longo M, Naderi J, Raciti GA, Desiderio A, Miele C, et al. Chronic Adipose Tissue Inflammation Linking Obesity to Insulin Resistance and Type 2 Diabetes. Front Physiol (2020) 10:1607. doi: 10.3389/fphys.2019.01607

7. Gleeson M, Bishop NC, Stensel DJ, Lindley MR, Mastana SS, Nimmo MA. The Anti-Inflammatory Effects of Exercise: Mechanisms and Implications for the Prevention and Treatment of Disease. Nat Rev Immunol (2011) 11:9. doi: $10.1038 /$ nri3041

8. Ghigliotti G, Barisione C, Garibaldi S, Fabbi P, Brunelli C, Spallarossa P, et al. Adipose Tissue Imune Response: Novel Triggers and Consequences for Chronic Inflammatory Conditions. Inflammation (2014) 37:4. doi: 10.1007/ s10753-014-9914-1

9. Giordano A, Murano I, Mondini E, Perugini J, Smorlesi A, Severi I, et al. Obese Adipocytes Show Ultrastructural Features of Stressed Cells and Die of Pyroptosis. J Lipid Res (2013) 54:9. doi: 10.1194/jlr.M038638

10. Vida C, González EM, de la Fuente M. Increase of Oxidation and Inflammation in Nervous and Immune Systems With Aging and Anxiety. Curr Pharm Des (2014) 20:29. doi: 10.2174/1381612820666140130201734

11. Fulop T, Larbi A, Dupuis G, Le Page A, Frost EH, Cohen AA, et al. Immunosenescence and Inflamm-Aging As Two Sides of the Same Coin: Friends or Foes? Front Immunol (2018) 8:1960. doi: 10.3389/fimmu.2017.01960

12. De La Fuente M, Castro NM. Obesity as a Model of Premature Immunosenescence. Curr Immunol Rev (2012) 8:1. doi: 10.2174/ 157339512798991290

13. Frasca D, Ferracci F, Diaz A, Romero M, Lechner S, Blomberg BB. Obesity Decreases B Cell Responses in Young and Elderly Individuals. Obes (Silver Spring) (2016) 24:3. doi: 10.1002/oby.21383

14. Burton D, Faragher R. Obesity and Type-2 Diabetes as Inducers of Premature Cellular Senescence and Ageing. Biogerontology (2018) 19:6. doi: 10.1007/ s10522-018-9763-7

15. Shirakawa K, Sano M. T Cell Immunosenescence in Aging, Obesity, and Cardiovascular Disease. Cells (2021) 10:9. doi: 10.3390/cells10092435

16. Arranz L, Lord JM, de la Fuente M. Preserved Ex Vivo Inflammatory Status and Cytokine Responses in Naturally Long-Lived Mice. Age (Dordr) (2010) 32:4. doi: 10.1007/s11357-010-9151-y

17. Hazeldine J, Lord JM. The Impact of Ageing on Natural Killer Cell Function and Potential Consequences for Health in Older Adults. Ageing Res Rev (2013) 12:4. doi: 10.1016/j.arr.2013.04.003 the Improvement of Higher Education Personnel (CAPES; grant $\left.\mathrm{n}^{\circ} 102164 / 2020-7\right)$.

\section{ACKNOWLEDGMENTS}

Furthermore, we thank the volunteers who have participated in this study.

18. Rodrigues LP, Teixeira VR, Alencar-Silva T, Simonassi-Paiva B, Pereira RW, Pogue R, et al. Hallmarks of Aging and Immunosenescence: Connecting the Dots. Cytokine Growth Factor Rev (2021) 59:9. doi: 10.1016/j.cytogfr.2021.01.006

19. Spielmann G, Johnston CA, O'Connor DP, Foreyt JP, Simpson RJ. Excess Body Mass Is Associated With T Cell Differentiation Indicative of Immune Ageing in Children. Clin Exp Immunol (2014) 176:2. doi: 10.1111/cei.12267

20. Wikby A, Maxson P, Olsson J, Johansson B, Ferguson FG. Changes in CD8 and CD4 Lymphocyte Subsets, T Cell Proliferation Responses and NonSurvival in the Very Old: The Swedish Longitudinal OCTO-Immune Study. Mech Ageing Dev (1998) 102:2-3. doi: 10.1016/s0047-6374(97)00151-6

21. Sales-Peres SHC, Azevedo-Silva LJ, Bonato RCS, Sales-Peres MC, Pinto ACS, Junior JFS. Coronavirus (SARS-CoV-2) and the Risk of Obesity for Critically Illness and ICU Admitted: Meta-Analysis of the Epidemiological Evidence. Obes Res Clin Pract (2020) 14:5. doi: 10.1016/j.orcp.2020.07.007

22. Karjala Z, Neal D, Rohrer J. Association Between HSV1 Seropositivity and Obesity: Data From the National Health and Nutritional Examination Surve2008. PloS One (2011) 6:5. doi: 10.1371/journal.pone.0019092

23. Sheridan PA, Paich HA, Handy J, Karlsson EA, Hudgens MG, Sammon AB, et al. Obesity Is Associated With Impaired Immune Response to Influenza Vaccination in Humans. Int J Obes (Lond) (2012) 36:8. doi: 10.1038/ ijo. 2011.208

24. Huttunem R, Syrjänem J. Obesity and the Risk and Outcome of Infection. Int J Obes (Lond) (2013) 37:333-40. doi: 10.1038/ijo.2012.62

25. Palmer AK, Tchkonia T, LeBrasseur NK, Chini EN, Xu M, Kirkland JL. Cellular Senescence in Type 2 Diabetes: A Therapeutic Opportunity. Diabetes (2015) 64:7. doi: 10.2337/db14-1820

26. Lau EYM, Carroll EC, Callender LA, Hood GA, Berryman V, Pattrick M, et al. Type 2 Diabetes Is Associated With the Accumulation of Senescent T Cells. Clin Exp Immunol (2019) 197:2. doi: 10.1111/cei.13344

27. Florindo AF, Latorre MRDO. Validação do Questionário De Baecke De Avaliação Da Atividade Física Habitual Em Homens Adultos. Rev Bras Med Esporte (2003) 9: 121-8.

28. Brown LE, Joseph P, Weir JP. Procedures Recommendation I: Accurate Assessment of Muscular Strength and Power. JEPonline (2001) 4:3. Available at: https://www.asep.org/asep/asep/Brown2.pdf.

29. Wasserman K, Whipp BJ, Koyal SN, Beaver WL. Anaerobic Threshold and Respiratory Gas Exchange During Exercise. J Appl Physiol (1973) 35:2. doi: 10.1152/jappl.1973.35.2.236

30. Pradella F, Boldrini VO, Marques AM, Moraes GAD, Francelin C, Cocenza RS, et al. Cytotoxic Activity of CD4 T Cells During the Early Stage of Autoimmune Neuroinflammation. BioRxiv (2020). doi: 10.1101/ 2020.03.10.985614

31. Salvestrini V, Sell C, Lorenzini A. Obesity May Accelerate the Aging Process. Front Endocrinol (2019) 10:266. doi: 10.3389/fendo.2019.00266

32. Reidy K, Kang HM, Hostetter T, Susztak K. Molecular Mechanisms of Diabetic Kidney Disease. J Clin Invest (2014) 124:6. doi: 10.1172/JCI72271

33. Ronan L, Alexander-Bloch AF, Wagstyl K, Farooqi S, Brayne C, Tyler LK, et al. Obesity Associated With Increased Brain Age From Midlife. Neurobiol Aging (2016) 47:63-70. doi: 10.1016/j.neurobiolaging.2016.07.010

34. Bandt JP, Monin C. Obesity, Nutrients and the Immune System in the Era of COVID-19. Nutrients (2021) 13:2. doi: 10.3390/nu13020610

35. Ventura MT, Casciaro M, Gangemi S, Buquicchio R. Immunosenescence in Aging: Between Immune Cells Depletion and Cytokines Up-Regulation. Clin Mol Allergy (2017) 15:21. doi: 10.1186/s12948-017-0077-0

36. Maurya R, Bhattacharya P, Dey R, Nakhasi HL. Leptin Functions in Infectious Diseases. Front Immunol (2018) 9:2741. doi: 10.3389/fimmu.2018.02741 
37. Junttila IS. Tuning the Cytokine Responses: An Update on Interleukin (IL)-4 and IL-13 Receptor Complexes. Front Immunol (2018) 9:888. doi: 10.3389/ fimmu.2018.00888

38. Heeb LEM, Egholm C, Impellizzieri D, Ridder F, Boyman O. Regulation of Neutrophils in Type 2 Immune Responses. Curr Opin Immunol (2018) 54:115-22. doi: 10.1016/j.coi.2018.06.009

39. Egholm C, Heeb LEM, Impellizzieri D, Boyman O. The Regulatory Effects of Interleukin-4 Receptor Signaling on Neutrophils in Type 2 Immune Responses. Front Immunol (2019) 10:2507. doi: 10.3389/fimmu.2019.02507

40. Heeb LEM, Egholm C, Boyman O. Evolution and Function of Interleukin-4 Receptor Signaling in Adaptive Immunity and Neutrophils. Genes Immun (2020) 21:143-9. doi: 10.1038/s41435-020-0095-7

41. Curfs JH, Meis JF, Hoogkamp-Korstanje JA. A Primer on Cytokines: Sources, Receptors, Effects, and Inducers. Clin Microbiol Rev (1997) 10:4. doi: 10.1128/ CMR.10.4.742

42. Williams A, Greene N, Kimbro K. Increased Circulating Cytokine Levels in African American Women With Obesity and Elevated HbA1c. Cytokine (2020) 128:154989. doi: 10.1016/j.cyto.2020.154989

43. Akbar AN, Henson SM. Are Senescence and Exhaustion Intertwined or Unrelated Processes That Compromise Immunity? Nat Rev Immunol (2011) 11:289-95. doi: 10.1038/nri2959

44. Wang Z, Aguilar EG, Luna JI, Dunai C, Khuat LT, Le CT, et al. Paradoxical Effects of Obesity on T Cell Function During Tumor Progression and PD-1 Checkpoint Blockade. Nat Med (2019) 25:141-51. doi: 10.1038/s41591-0180221-5

45. Zindy F, Quelle DE, Roussel MF, Sherr CJ. Expression of the P16 ${ }^{\text {ink4a }}$ Tumor Suppressor Versus Other INK4 Family Members During Mouse Development and Aging. Oncogene (1997) 15:2. doi: 10.1038/sj.onc.1201178

46. Ressler S, Bartkova J, Niederegger H, Bartek J, Scharffetter-Kochanek K, Jansen-Durr P, et al. P16ink4a Is a Robust In Vivo Biomarker of Cellular Aging in Human Skin. Aging Cell (2006) 5:5. doi: 10.1111/j.14749726.2006.00231.x

47. Hara E, Smith R, Parry D, Tahara H, Stone S, Peters G. Regulation of P16cdkn2 Expression and Its Implications for Cell Immortalization and Senescence. Mol Cell Biol (1996) 16:3. doi: 10.1128/mcb.16.3.859

48. Zhu D, Xu G, Ghandhi S, Hubbard K. Modulation of the Expression of P16ink4a and P14arf by hnRNP A1 and A2 RNA Binding Proteins: Implications for Cellular Senescence. J Cell Physiol (2002) 193:1. doi: 10.1002/jcp.10147

49. Wu J, Xue L, Weng M, Sun Y, Zhang Z, Wang W, et al. Sp1 is Essential for P16 ${ }^{\text {ink } 4 \text { a }}$ Expression in Human Diploid Fibroblasts During Senescence. PloS One (2007) 2:1. doi: 10.1371/journal.pone.0000164

50. Ksiazek K, Piwocka K, Brzezinska A, Sikora E, Zabel M, Breborowicz A, et al. Early Loss of Proliferative Potential of Human Peritoneal Mesothelial Cells in Culture: The Role of P16ink4-mediated Premature Senescence. J Appl Physiol (2006) 100:3. doi: 10.1152/japplphysiol.01086.2005

51. Quereda V, Martinalbo J, Dubus P, Carnero A, Malumbres M. Genetic Cooperation Between p21Cip1 and INK4 Inhibitors in Cellular Senescence and Tumor Suppression. Oncogene (2007) 26:55. doi: 10.1038/sj.onc.1210578

52. Canepa ET, Scassa ME, Ceruti JM, Marazita MC, Carcagno AL, Sirkin PF, et al. INK4 Proteins, a Family of Mammalian CDK Inhibitors With Novel Biological Functions. IUBMB Life (2007) 59:7. doi: 10.1080/ 15216540701488358

53. Fordyce C, Fessenden T, Pickering C, Jung J, Singla V, Berman H, et al. DNA Damage Drives an Activin a-Dependent Induction of Cyclooxygenase-2 in Premalignant Cells and Lesions. Cancer Prev Res (Phila) (2010) 3:2. doi: 10.1158/1940-6207.CAPR-09-0229

54. Romagosa C, Simonetti S, López-Vicente L, Mazo A, Lleonart ME, Castellvi J, et al. p16 ${ }^{\text {Ink4a }}$ Overexpression in Cancer: A Tumor Suppressor Gene Associated With Senescence and High-Grade Tumors. Oncogene (2011) 30:2087-97. doi: 10.1038/onc.2010.614
55. Gustafson MP, DiCostanzo AC, Wheatley CM, Kim C, Bornschlegl S, Gastineau DA, et al. A Systems Biology Approach to Investigating the Influence of Exercise and Fitness on the Composition of Leukocytes in Peripheral Blood. J ImmunoTher Cancer (2019) 5:30. doi: 10.1186/s40425017-0231-8

56. Effros RB, Walford RL. T Cell Cultures and the Hayflick Limit. Hum Immunol (1984) 9:1. doi: 10.1016/0198-8859(84)90006-5

57. Larbi A, Fulop T. From "Truly Naïve" to "Exhausted Senescent" T Cells: When Markers Predict Functionality. Cytometry A (2014) 85:1. doi: 10.1002/ cyto.a.22351

58. Colonna-Romano G, Bulati M, Aquino A, Scialabba G, Candore G, Lio D, et al. Mech. Ageing Dev (2003) 124:4. doi: 10.1016/s0047-6374(03)00013-7

59. Khan SH, Hemann EA, Legge KL, Norian LA, Badovinac VP. Diet-Induced Obesity Does Not Impact the Generation and Maintenance of Primary Memory CD8 T Cells. J Immunol (2014) 193:12. doi: 10.4049/ jimmunol.1401685

60. Li Y, Qiu X, Zhang S, Zhang Q, Wang E. Hypoxia-Induced CCR7 Expression via HIF- $1 \alpha$ and HIF-2 $\alpha$ Correlates With Migration and Invasion in Lung Cancer Cells. Cancer Biol Ther (2009) 8:4. doi: 10.4161/cbt.8.4.7332

61. Hirao M, Onai N, Hiroishi K, Watkins SC, Matsushima K, Robbins PH, et al. CC Chemokine Receptor-7 on Dendritic Cells is Induced After Interaction With Apoptotic Tumor Cells: Critical Role in Migration From the Tumor Site to Draining Lymph Nodes. Cancer Res (2000) 60(8):2209-17. Available at: https://cancerres.aacrjournals.org/content/60/8/2209.

62. Muller A, Homey B, Soto H, Ge N, Catron D, Buchanan ME, et al. Involvement of Chemokine Receptors in Breast Cancer Metastasis. Nature (2001) 410:6824. doi: 10.1038/35065016

63. Hellman J, Sansbury BE, Holden CR, Tang Y, Wong B, Wysoczynski M, et al. CCR7 Maintains Nonresolving Lymph Node and Adipose Inflammation in Obesity. Diabetes (2016) 65:8. doi: 10.2337/db15-1689

64. Catalán V, Gómez-Ambrosi J, Ramirez B, Rotellar F, Pastor C, Silva C, et al. Proinflammatory Cytokines in Obesity: Impact of Type 2 Diabetes Mellitus and Gastric Bypass. Obes Surg (2007) 17:11. doi: 10.1007/s11695-008-9424-Z

65. Telle-Hansen VH, Halvorsen B, Dalen KT, Narverud I, Wesseltoft-Rao N, Granlund L, et al. Altered Expression of Genes Involved in Lipid Metabolism in Obese Subjects With Unfavourable Phenotype. Genes Nutr (2013) 8:4. doi: 10.1007/s12263-012-0329-z

66. Catalán V, Gómez-Ambrosi J, Rodríguez A, Ramírez B, Valentí V, Moncada R, et al. Peripheral Mononuclear Blood Cells Contribute to the ObesityAssociated Inflammatory State Independently of Glycemic Status: Involvement of the Novel Proinflammatory Adipokines Chemerin, Chitinase-3-Like Protein 1, Lipocalin-2 and Osteopontin. Genes Nutr (2015) 10:3. doi: $10.1007 / \mathrm{s} 12263-015-0460-8$

Conflict of Interest: The authors declare that the research was conducted in the absence of any commercial or financial relationships that could be construed as a potential conflict of interest.

Publisher's Note: All claims expressed in this article are solely those of the authors and do not necessarily represent those of their affiliated organizations, or those of the publisher, the editors and the reviewers. Any product that may be evaluated in this article, or claim that may be made by its manufacturer, is not guaranteed or endorsed by the publisher.

Copyright (C) 2022 Brunelli, Boldrini, Bonfante, Duft, Mateus, Costa, Chacon-Mikahil, Teixeira, Farias and Cavaglieri. This is an open-access article distributed under the terms of the Creative Commons Attribution License (CC BY). The use, distribution or reproduction in other forums is permitted, provided the original author(s) and the copyright owner(s) are credited and that the original publication in this journal is cited, in accordance with accepted academic practice. No use, distribution or reproduction is permitted which does not comply with these terms. 